Esta revista forma parte del acervo de la Biblioteca Jurídica Virtual del Instituto de Investigaciones Jurídicas de la UNAM

\title{
LA JURISPRUDENCIA EN CUBA: RECONOCIMIENTO DENTRO DEL SISTEMA DE FUENTES DEL DERECHO Y POSIBLES CONSEGUENGIAS*
} JURISPRUDENCE IN CUBA: RECOGNITION WITHIN THE SOURCES OF LAW AND POSSIBLE CONSEQUENCES

\section{Carlos Justo BRUZÓn VILTRES** \\ Iraida R. TAMAYO BLANCO***}

RESUMEN: En Cuba no existe una determinación formal y explícita de las fuentes del derecho. En la actualidad, sin embargo, más allá del acto normativo como única vía reconocida para la creación del derecho, se manifiestan otras formas, entre las que se encuentra la jurisprudencia. En el presente artículo se analizan algunos elementos que sustentan la posibilidad y la necesidad de su reconocimiento en el ordenamiento jurídico cubano y las consecuencias derivadas de este hecho, a partir de su desarrollo en distintos momentos históricos, las principales posiciones y polémicas en el ámbito doctrinal interno - fundamentalmente- en torno a su identificación y sus manifestaciones concretas en el ámbito judicial cubano.

Palabras clave: jurisprudencia; fuentes del derecho; fuentes formales; ordenamiento jurídico cubano; sistema judicial en Cuba.
ABSTRACT: In Cuba there is no formal and explicit determination of the sources of Law. At present, however, beyond the normative act as only way for the creation of Law, exists other forms, among which is the jurisprudence. This article discusses some elements that sustain the possibility and necessity of its recognition in the Cuban legal system and the consequences of this fact, since the development of the jurisprudence in different historical moments, the main positions and doctrinal controversies - especially in the Cuban academic circles-, and its concrete manifestation in the judicial system in Cuba.

Keyreords: Furisprudence; Sources of Law, Formal Sources; Cuban Legal System; Zudicial System in Cuba.

* Artículo recibido el 1o. de septiembre de 2012 y aceptado para su publicación el 24 de julio de 2013.

** Profesor de Teoría del Estado y del derecho. Decano de la Facultad de Ciencias Sociales y Humanísticas de la Universidad de Granma y miembro asociado de la Academia de Ciencias de Cuba.

*** Ayudante de profesor de Teoría general del derecho y Bases históricas y teóricas de los sistemas jurídicos actuales, Departamento de Derecho, Universidad de Granma, Cuba.

Boletín Mexicano de Derecho Comparado, nueva serie, año XLVII, núm. 139, enero-abril de 2014, pp. 251-283.

D. R. (C) 2014. UNAM, Instituto de Investigaciones Jurídicas. 
Esta revista forma parte del acervo de la Biblioteca Jurídica Virtual del Instituto de Investigaciones Jurídicas de la UNAM

SUMARIO: I. Introducción. II. Aspectos generales sobre la manifestación de las fuentes en el ordenamiento jurídico cubano. III. Análisis del reconocimiento de la jurisprudencia en el sistema jurídico cubano en distintos momentos históricos. IV. Polémicas respecto al reconocimiento de la jurisprudencia como fuente formal del derecho en Cuba. V. Manifestaciones de la jurisprudencia en el contexto normativo y en la labor judicial en Cuba. Papel del Tribunal Supremo de Justicia y su Consejo de Gobierno. VI. Posibles consecuencias del reconocimiento de la jurisprudencia como fuente del derecho en el ordenamiento jurídico cubano. VII. Conclusiones.

VIII. Bibliografia.

\section{INTRODUCGIÓN}

El problema de las fuentes del derecho constituye uno de los temas que, desde la perspectiva teórica, aún generan polémicas y dificultades. Este hecho no sólo se confirma en la doctrina jurídica extranjera, sino que incluso alcanza a la realidad cubana, en especial durante el actual proceso de perfeccionamiento institucional en el cual, sin duda, posee un valor indiscutible el derecho como ciencia y como práctica.

En Cuba no existe una definición categórica de las vías por las cuales se origina el fenómeno jurídico, que es en esencia el concepto más general de la categoría fuente. Ha prevalecido durante un largo periodo la idea de que sólo el acto normativo, como derecho positivo y escrito, es la única manifestación de la creación jurídica, pero ni siquiera este reconocimiento se ha hecho explícito en algunas de las disposiciones normativas de más alto rango, en particular la Constitución.

Esta cuestión parte de la propia diversidad conceptual en cuanto al término fuentes del derecho. De la multiplicidad de clasificaciones (entre las que se encuentran, por ejemplo, las denominadas fuentes de autoridad creadora, fuentes de conocimiento, fuentes estatales y extraestatales o extralegales, entre muchas otras), ha sido el par fuentes materiales/fuentes formales el que mayor atención ha deparado en los estudios, de por sí escasos en el ámbito jurídico nacional, sobre esta temática.

Dentro de las denominadas fuentes formales ${ }^{1}$ aparece la jurisprudencia, entendida desde diversos puntos de vista, según el sistema de derecho de referencia.

1 Cfr., inter alia, Guastini, Riccardo, Concepciones de las fuentes del derecho, Italia, Universidad de Génova, 1993, p. 106; García Máynez, Eduardo, Introducción al estudio del derecho, D. R. (C) 2014. UNAM, Instituto de Investigaciones Jurídicas, Boletin Mexicano de Derecho Comparado, núm. 139, pp. 251-283. 
Esta revista forma parte del acervo de la Biblioteca Jurídica Virtual del Instituto de Investigaciones Jurídicas de la UNAM

A lo largo de la evolución histórica de esta figura, disímiles han sido sus definiciones, pero en sentido general ha sido asociada a la creación judicial del derecho, al resultado de la actividad de los órganos judiciales. Este hecho varía según los regímenes jurídicos en que se manifieste y, en consecuencia, reconocida o no como fuente de derecho. Así, por ejemplo, en el sistema anglosajón adquiere forma a través de los precedentes judiciales, que resultan obligatorios para el resto de los jueces, y constituyen, al mismo tiempo, la vía generadora del derecho por excelencia.

Desde otra óptica se ha entendido a la jurisprudencia como la reiteración de fallos, provenientes esencialmente de los órganos superiores de justicia; las disposiciones de los más altos tribunales que resultan vinculantes para los de inferior jerarquía; como uno de los planos de la ciencia jurídica o, en el sentido técnico, para identificar la labor judicial propiamente dicha. Este término ha sido empleado, incluso, para identificar los estudios jurídicos (v. gr., Escuela de Jurisprudencia). Estas manifestaciones nos ofrecen una visión de la polisemia existente en la palabra jurisprudencia, cuyo uso tiene sus orígenes en los inicios mismos del proceso de formación del derecho, con un hito fundamental en el mundo grecolatino antiguo.

Uno de los aspectos más polémicos respecto a esta categoría ha estado vinculado, precisamente, a su reconocimiento o no, como fuente formal del derecho. El punto más álgido de la discusión sobrevino con la instauración de los regímenes liberales burgueses de finales del siglo XVIII e inicios del siglo XIX, principalmente en Europa. Una de las consecuencias inmediatas del triunfo revolucionario sobre el absolutismo monárquico fue la abolición de la vieja estructura de poder del Estado y la exacerbación del sentimiento de desconfianza hacia los jueces, otrora defensores del sistema monárquico. Con la implantación del principio de soberanía popular y de la representación como su expresión práctica y, al mismo tiempo, de supremacía de la ley y del legislador, el producto de la actividad judicial fue desconocido como creador de derecho.

Desde entonces las disputas teóricas han girado en torno al papel del juez y de los tribunales en el proceso de creación normativa frente a un criterio relativamente dominante de su reducción a la boca muda que se

32a. ed., México, Porrúa, 1980, p. 51; Hübner Gallo, Jorge Iván, "Fuentes y formas de expresión del derecho", Introducción al derecho, Santiago de Chile, Editorial Jurídica de Chile, 1976, p. 145; Legaz Lacambra, Luis, Filosofia del derecho, Barcelona, Bosch, 1961, pp. 487 y ss. 
Esta revista forma parte del acervo de la Biblioteca Jurídica Virtual del Instituto de Investigaciones Jurídicas de la UNAM

pronuncia solo en nombre de la ley, encerrado en el dogma de la subsunción, como intérprete y aplicador del derecho, pero nunca como sujeto activo de su creación.

Esta noción se ha desarrollado fundamentalmente en los países del sistema continental. Sin embargo, el proceso de formación y funcionamiento de los tribunales constitucionales, y el papel cada vez más protagónico de los órganos judiciales de superior jerarquía en los escenarios donde no existe aquella jurisdicción especial, han contribuido a reconocer nuevas manifestaciones de creación judicial del derecho y, desde el punto de vista técnico, de jurisprudencia en el sentido de formación de normas jurídicas.

En el caso de Cuba, este hecho no es ajeno a la práctica y al debate doctrinal. Respecto a la jurisprudencia pueden identificarse varios periodos en los que se le ha otorgado valor o no dentro del sistema de fuentes del derecho, que se expondrán de manera general en el cuerpo de este artículo.

Actualmente, a través de la labor del Tribunal Supremo Popular (en particular su Consejo de Gobierno) pueden advertirse expresiones concretas que guardan una estrecha relación con la conformación de la jurisprudencia en el sentido de fuente creadora de normas jurídicas. Estas actuaciones sobrepasan, en nuestro entendimiento, en alguna medida la labor interpretativa de este órgano, creando efectivamente normas de carácter vinculante que, en muchos casos, contribuyen a llenar también algunos vacíos normativos.

En consecuencia, estos elementos configuran el abordaje de una problemática social que guarda relación con las dificultades existentes en relación con el funcionamiento de nuestro sistema jurídico, que afectan las características esenciales del ordenamiento jurídico (unidad, coherencia y plenitud) y, en sentido general, su funcionamiento sistémico. Por esta razón se vuelve necesario evaluar o determinar las posibles consecuencias del reconocimiento de las fuentes formales, en especial la jurisprudencia, para nuestro sistema jurídico, objetivo que se plantea como centro de impulsión de este estudio. 
Esta revista forma parte del acervo de la Biblioteca Jurídica Virtual del Instituto de Investigaciones Jurídicas de la UNAM

\section{ASPECTOS GENERALES SOBRE LA MANIFESTACIÓN DE LAS FUENTES EN EL ORDENAMIENTO JURÍDICO GUBANO²}

En Cuba, la Constitución y el Código Civil ${ }^{3}$ no contienen ningún precepto que haga alusión expresa al sistema de fuentes del derecho, punto cardinal sobre el cual se asienta la construcción jurídica del país. Debe señalarse que, si bien no se hace explícitamente, se establece en la Constitución, en los artículos correspondientes a los órganos con facultades normativas y el tipo de norma que crean, el reconocimiento a la ley o acto normativo como única fuente del derecho en Cuba.

Es por ello que en el contexto cubano no caben dudas acerca de que la ley es la regla suprema del ordenamiento jurídico, de aplicación preferente. Estas son las normas nacidas de la potestas normandi del Estado; las normas de origen estatal decretadas por la organización política. ${ }^{4}$

En nuestro ordenamiento jurídico la ley en sentido formal es la que proviene del órgano legislativo, o sea, la aprobada por la Asamblea Nacional del Poder Popular, al tenor del artículo 75 inciso b) de la Constitución.

No corren con igual suerte las otras fuentes formales del derecho. Refiriéndose a la costumbre, autores como Cañizares Abeledo ${ }^{5}$ son partidarios de su supresión como fuente del derecho civil y la inoperancia histórica de la misma, razones respecto a las cuales difieren algunos autores, como Fernández Bulté, quien opina que "en nuestro sistema igualmente se pueden generar costumbres, hábitos, maneras de proceder sumamente humanas,

2 Proponemos, apenas, un acercamiento a esta cuestión. Con un desarrollo más amplio, además de algunas obras colectivas cubanas citadas en este estudio, véase Pérez Carrillo, Juan R., "Causas de indeterminación en el sistema de fuentes del derecho", Problema. Anuario de Filosofia y Teoría del Derecho, México, UNAM, Instituto de Investigaciones Jurídicas, núm. 4, 2010, pp. 303-322; id., "Hacia un reconocimiento jurídico-normativo de las fuentes del derecho en Cuba", Iuris Veritatis, Perú, núm. 1, 2009, pp. 13-17.

3 Generalmente se insiste en la relación de las fuentes con el Código Civil, a partir del carácter supletorio que tiene éste respecto al resto del sistema jurídico, operando a modo de derecho común, como se establece en el artículo 8o. y la Disposición Final Primera del citado cuerpo normativo: "Las disposiciones de este Código son supletorias respecto a materias civiles u otras reguladas en leyes especiales".

4 Cfr. Díez Picazo, Luis y Gullón, Antonio, Sistema de derecho Civil, 8a. ed., Madrid, Tecnos, 1994, vol. I, pp. 102 y 103.

5 Cañizares Abeledo, Fernando, Teoría del derecho, La Habana, Editorial Pueblo y Educación, 1979, p. 73.

D. R. C 2014. UNAM, Instituto de Investigaciones Jurídicas, Boletín Mexicano de Derecho Comparado, núm. 139, pp. 251-283. 
Esta revista forma parte del acervo de la Biblioteca Jurídica Virtual del Instituto de Investigaciones Jurídicas de la UNAM

paradigmáticamente solidarias y, en consecuencia, no todas las costumbres de la sociedad en que vivimos son rezagos conductuales del pasado". ${ }^{6}$

Por otra parte, los principios generales del derecho tampoco son reconocidos como fuentes, aunque no se puede obviar su aplicación dentro del ordenamiento jurídico. Estos principios desempeñan una función de informadores del ordenamiento jurídico y constituyen su fundamento, y de alguna manera están contenidos en la propia legislación sustantiva, entre los que cabe mencionar (citando sólo algunos ejemplos del Código Civil cubano) el principio de condena al ejercicio abusivo del derecho ( $c f r$ artículo 4o.); el de la buena fe (cfr. artículo 6o.); el de protección de la persona (cfr. artículo 38); el de responsabilidad civil por daño causado ( $c f r$. artículos 81); el de consensualidad en materia contractual (cfr. artículos 310 y 313 ), entre otros.

Con respecto a la jurisprudencia, las variaciones en cuanto al reconocimiento de la misma como fuente de derecho han sido visibles. En la época pre-revolucionaria existió un sector doctrinal que defendió su valor en el ordenamiento jurídico, como reflejaron en sus momentos las posiciones de del Cueto, Jiménez de Asúa o Sánchez de Bustamante, considerasen unos u otros su carácter formal o indirecto.

Sin embargo, se ha sostenido, como ha expresado el profesor Fernández Bulté, que en "la Cuba de la Revolución está absolutamente dirimido que la jurisprudencia o la doctrina legal no es fuente formal de derecho", ${ }^{7}$ aunque advierte sobre la importancia de prestar atención a las consideraciones doctrinales que se van estableciendo por las distintas salas del Tribunal Supremo Popular (TSP), y la institución del recurso de casación.

La realidad, tanto desde la teoría como desde la práctica jurídica cubana, nos va informando que es menester actualizar este criterio, sobre todo en función del necesario enfoque sistémico de nuestro ordenamiento jurídico y de su correspondiente funcionamiento armónico.

Un grupo de autores cubanos, ${ }^{8}$ con diversidad de perspectiva por las disciplinas en que se desarrolla su obra científica y pedagógica, nos va ilustrando que el tema de la jurisprudencia debe ganar espacio en el debate

6 Fernández Bulté, Julio, Teoría del Estado y el derecho, La Habana, Editorial Félix Varela, 2004, t. II, pp. 63 y 64.

7 Ibidem, p. 73.

8 Cabe destacar las opiniones de Juan Mendoza Díaz, Andry Matilla Correa y Martha Prieto Valdés, expuestas esencialmente en la literatura de referencia, y que en mayor D. R. (C) 2014. UNAM, Instituto de Investigaciones Jurídicas, Boletín Mexicano de Derecho Comparado, núm. 139, pp. 251-283. 
Esta revista forma parte del acervo de la Biblioteca Jurídica Virtual del Instituto de Investigaciones Jurídicas de la UNAM

sobre los medios de creación del derecho, en especial a partir de la labor judicial, y del papel que desempeña el máximo órgano de justicia del país, el Tribunal Supremo Popular, a la vez de contrarrestar la notable sequía doctrinal existente sobre el tema, verificada en los pocos estudios actuales acerca de las fuentes del derecho y la jurisprudencia en particular.

Un primer elemento de acercamiento a esta fuente formal está relacionado con las formas de expresarse la jurisprudencia en el sistema romano-germánico-francés. En este sistema, por ejemplo, puede entenderse como jurisprudencia o doctrina legal la reiteración de fallos del máximo órgano de justicia (en número superior a dos, como reflejan algunos ordenamientos). ${ }^{9}$

Otra variante, como nos explica Matilla Correa, consiste en:

... atribuirle a una estructura del Tribunal Supremo, que no es propiamente una de las salas en que éste se divide, sino otra estructura, que por su naturaleza y funciones... pueda tomar decisiones que la coloquen por encima de las referidas salas, la posibilidad de adoptar decisiones revestidas de carácter obligatorio, tanto para esas salas, como para todo el sistema de órganos judiciales, por las que sienta reglas de derecho. ${ }^{10}$

Suele hablarse en este caso del Pleno del Tribunal o Tribunal Pleno, pero que en el específico caso de Cuba es el Consejo de Gobierno del Tribunal Supremo Popular.

Estas decisiones, que son la base de una potestad de creación normativa del tribunal superior, no se traducen en sentencias reiteradas, sino que se formalizan en instrumentos jurídicos como acuerdos, instrucciones, dictámenes, entre otros, que sirven de directrices y unifican el modo de actuación del resto de los tribunales.

En la actualidad las facultades antes mencionadas, que residen en el Consejo de Gobierno del Tribunal Supremo Popular, constituyen una manifestación de la creación formal de normas imperativas, que suplen la

o menor extensión, introducen elementos de notable relevancia para el análisis de esta institución.

9 Para un amplio sector doctrinal esta es la única y verdadera forma de manifestación jurisprudencial en el derecho continental.

10 Matilla Correa, Andry, "Comentarios sobre las fuentes del derecho administrativo cubano", en Matilla Correa, Andry et al., Temas de derecho administrativo, La Habana, Editorial Félix Varela, 2004, p. 109.

D. R. C 2014. UNAM, Instituto de Investigaciones Jurídicas, Boletín Mexicano de Derecho Comparado, núm. 139, pp. 251-283. 
Esta revista forma parte del acervo de la Biblioteca Jurídica Virtual del Instituto de Investigaciones Jurídicas de la UNAM

jurisprudencia derivada de la reiteración de fallos de este órgano, y aunque se ha cerrado el paso a la creación judicial de normas por interpretación directa de la Constitución, no ha sucedido así respecto a las leyes, ni puede negarse tanto el carácter armonizador como el valor que posee la interpretación judicial, que a la postre se manifiesta en cuanto actividad jurisprudencial y, al mismo tiempo, sienta pautas jurídicas.

$\mathrm{Al}$ respecto, Prieto Valdés expresa que:

En la práctica jurídica cubana la jurisprudencia, aun cuando no es reconocida teóricamente como fuente de derecho, sí lo es en la variante de disposición creada por el órgano de administración judicial superior... Dictámenes y acuerdos del Consejo de Gobierno del Tribunal Supremo Popular, en tanto normativas obligatorias, ${ }^{11}$ y por medio de las cuales se fijan determinadas pautas interpretativas para todos los tribunales en el país, y a través de ellas integran y adecuan... el derecho conforme a las nuevas condiciones sociales y preservando su eficacia social. ${ }^{12}$

\section{ANÁLISIS DEL RECONOGIMIENTO DE LA JURISPRUDENCIA EN EL SISTEMA JURÍDICO CUBANO EN DISTINTOS MOMENTOS HISTÓRICOS}

El reconocimiento de la jurisprudencia como fuente en el sistema jurídico cubano ha estado marcado por la influencia y el carácter determinante que han ejercido las metrópolis que nos dominaron, primero durante la conquista y colonización española, y luego en la República intervencionista estadounidense o periodo neocolonial. Claro está que para llegar a un criterio más completo de este reconocimiento es necesario hacer referencia a las Constituciones instauradas y al lugar que ocupó la creación judicial del derecho en las distintas etapas históricas.

Sería adecuado comenzar señalando que la historia constitucional cubana puede ser periodizada atendiendo a criterios distintos; sin embargo,

11 Cfr. Constitución de la República, artículo 121, pfo. 3.

$12 \mathrm{Al}$ respecto, véase Prieto Valdés, Martha, La Interpretación del derecho. Criterios doctrinales y su expresión en Cuba, La Habana, s. e., 1999.

D. R. (C) 2014. UNAM, Instituto de Investigaciones Jurídicas,

Boletín Mexicano de Derecho Comparado, núm. 139, pp. 251-283. 
Esta revista forma parte del acervo de la Biblioteca Jurídica Virtual del Instituto de Investigaciones Jurídicas de la UNAM

preferimos enfocarnos en la postura de Villabella Armengol, ${ }^{13}$ a partir de las fuentes en el derecho constitucional cubano, las cuales pueden clasificarse en las del constitucionalismo español, los proyectos constitucionales criollos, las Constituciones mambisas, las Constituciones liberal-burguesas y las Constituciones de la etapa revolucionario-socialista.

\section{Etapa colonial}

En este periodo se encuentra el constitucionalismo español, los proyectos constitucionales criollos y las constituciones mambisas.

Las Constituciones españolas que se hicieron extensivas a Cuba, dado su condición de colonia, fueron el Estatuto de Bayona, la Constitución de Cádiz, el Estatuto Real de 1834 y la Constitución Autonómica de las islas de Cuba y Puerto Rico de 1897. En éstas no se delineaba un sistema de fuentes del derecho preciso y tampoco se particularizaba en el valor de la jurisprudencia.

Entre estos proyectos constitucionales criollos encontramos el de Francisco de Arango y Parreño (1811), el proyecto del presbítero José Agustín Caballero (1811), el de Félix Varela (1823), el de Gabriel Claudio de Zequeira (1822), el proyecto constitucional separatista de Joaquín Infante (1812) y el proyecto de Narciso López (1851). En ellos no existe una línea definida en torno al valor de la jurisprudencia y, debido igualmente al escaso desarrollo en materia de técnica jurídica presente en la mayoría, no es de sorprender la ausencia de una estricta mención a las fuentes formales del nuevo derecho que se pretendía instaurar al margen del ya existente, de origen colonial.

Respecto a las Constituciones mambisas deben destacarse las dos primeras, promulgadas durante la Guerra de Independencia de los Diez Años: la Constitución de Guáimaro ${ }^{14}$ y la Constitución de Baraguá, ${ }^{15}$ así

13 Véase Villabella Armengol, Carlos Manuel, "Historiografía del poder político en Cuba: forma de gobierno en el constitucionalismo cubano", en Matilla Correa, Andry (coord.), Estudios sobre historia del derecho en Cuba, La Habana, Editorial Ciencias Sociales, 2009, p. 138.

14 Es aprobada en abril de 1869 en el seno de la Asamblea de Guáimaro.

15 Es proclamada el 23 de marzo de 1878, como respuesta al Pacto de Zanjón que puso fin a la Constitución de Guáimaro.

D. R. (C) 2014. UNAM, Instituto de Investigaciones Jurídicas, Boletín Mexicano de Derecho Comparado, núm. 139, pp. 251-283. 
Esta revista forma parte del acervo de la Biblioteca Jurídica Virtual del Instituto de Investigaciones Jurídicas de la UNAM

como las dos últimas en la segunda gesta, es decir, en la de 1895: la Constitución de Jimaguayú ${ }^{16}$ y la Constitución de la Yaya. ${ }^{17}$

Lo cierto es que en ninguna de estas Constituciones queda establecido explícitamente el sistema de fuentes del derecho; si bien se establecieron, en algunas, los órganos de poder del Estado encargados del ejercicio Legislativo y Judicial. No obstante, a finales de la década de 1880, con la aprobación del Código Civil español, se extendió a Cuba la aplicación de sus preceptos (Real Decreto de 24 de julio de 1889, que dispone su publicación), entre los que sobresale el artículo 1.6, donde se determinaba, dentro del sistema de fuentes, que "la jurisprudencia complementará el ordenamiento jurídico con la doctrina que, de modo reiterado, establezca el Tribunal al interpretar y aplicar la ley, la costumbre y los principios generales del derecho".

\section{2. $1901-1940$}

La etapa siguiente de la historia constitucional de Cuba es la del momento del nacimiento de la República neocolonial, después del periodo de ocupación estadounidense.

$\mathrm{Al}$ cesar la soberanía española sobre la Isla y comenzar la ocupación, el gobernador militar en su Proclama del 19 de enero de 1899 mantuvo la vigencia de los códigos Civil y Criminal. Más tarde, la disposición transitoria de la Constitución de 1901 reprodujo tal criterio. Es por ello que durante esta etapa van a estar vigentes las fuentes formales del derecho anteriormente reconocidas, pero va a alcanzar transcendental importancia la jurisprudencia, vista a partir de este momento como precedente judicial debido a que la estructura jurídica del país se encontrará ligada a sucesos históricos en los que el gobierno estadounidense es el protagonista.

De tal forma, inspirados en la norma suprema estadounidense, los constituyentes cubanos de 1901 aprobaron una Constitución que establecía un régimen republicano y representativo, estructurado en el sistema de división de poderes (Ejecutivo, Legislativo y Judicial), con un presidente de la República, un Congreso formado por el Senado y la Cámara de Re-

16 Adoptada el 16 de septiembre de 1895.

17 Fue firmada y promulgada el 29 de octubre de 1897 como consecuencia de la cláusula de reforma de la Constitución de Jimaguayú.

D. R. (C) 2014. UNAM, Instituto de Investigaciones Jurídicas,

Boletín Mexicano de Derecho Comparado, núm. 139, pp. 251-283. 
Esta revista forma parte del acervo de la Biblioteca Jurídica Virtual del Instituto de Investigaciones Jurídicas de la UNAM

presentantes y el Poder Judicial cuyo más alto organismo era el Tribunal Supremo.

Con respecto al Poder Judicial, advertimos que la Constitución en su título X lo regula. Al decir de Carreras ${ }^{18}$ el Tribunal Supremo de Justicia tenía, entre sus atribuciones, conocer los recursos de casación; dirimir las competencias entre los tribunales; conocer de los juicios de los que litigaran entre sí el Estado, las provincias y los municipios, así como decidir sobre la constitucionalidad de las leyes, decretos y reglamentos, cuando fuese objeto de controversia entre partes.

Con la segunda ocupación militar nacen las leyes orgánicas del Poder Ejecutivo, del Judicial, de las provincias y los municipios. La ley española de lo contencioso-administrativo continúa en vigor, con algunas modificaciones. ${ }^{19}$

La Ley Constitucional de 1934 amplió las atribuciones del Tribunal Supremo de Justicia en esta materia, al facultarlo para decidir sobre la constitucionalidad de las leyes y otras disposiciones, tanto a petición de la parte afectada, como ante solicitud suscrita por 25 ciudadanos que se encontrasen en pleno goce y ejercicio de sus derechos civiles y políticos. ${ }^{20}$ De forma expresa se reconoció el recurso de inconstitucionalidad, en el cual el Tribunal debería resolver siempre el fondo de la reclamación y cuya decisión tendría efectos erga omnes, así como admitió la acción pública para iniciar el proceso.

A partir de este momento, el precitado recurso "adquiere una nueva significación y asume un sentido jurídico político [que se encaminó] a la defensa del régimen constitucional vigente frente a las reformas ilegales producidas con anterioridad". ${ }^{21}$ Abundante jurisprudencia se generó en este periodo, a partir de estas modificaciones.

18 Véase Carreras, Julio, Historia del Estado y el derecho en Cuba, La Habana, Editorial Pueblo y Educación, 1985, p. 360.

19 Véase Álvarez Tabío, Fernando, El proceso contencioso administrativo, La Habana, s. e., 1954, p. 36.

20 Véase Barreras, Antonio, "Ley Constitucional de 1934", Textos de las Constituciones de Cuba (1812-1940), La Habana, Minerva, 1940, p. 353.

21 Álvarez Tabío, Fernando, El recurso de inconstitucionalidad, La Habana, Librería Martí, 1960, p. 137.

D. R. (C) 2014. UNAM, Instituto de Investigaciones Jurídicas, Boletín Mexicano de Derecho Comparado, núm. 139, pp. 251-283. 
Esta revista forma parte del acervo de la Biblioteca Jurídica Virtual del Instituto de Investigaciones Jurídicas de la UNAM

Esta última etapa arranca con la Constitución de 1940, promulgada el 5 de julio de dicho año. Con respecto al control de constitucionalidad, la carta magna de 1940 refrendaba en la sección tercera, dentro del título XIV, en relación con el Poder Judicial, la creación al interior del Tribunal Supremo de Justicia (TSJ), de una Sala, en la cual quedaba conformado el Tribunal de Garantías Constitucionales y Sociales. ${ }^{22}$

Constitucionalmente estaba plasmado que este Tribunal de Garantías era un órgano competente que podía conocer no sólo de los recursos de inconstitucionalidad, sino que también tenía conocimiento sobre diversos asuntos, como cuestiones relativas a la legislación social y los recursos contra los abusos de poder (cfr. artículo 182).

De la Sala se desprendieron importantes decisiones judiciales que, en su momento, surtieron el efecto propio de las jurisdicciones mixtas, con cercanía igualmente al modelo europeo del que hoy se tiene como paradigma de la ruptura del pensamiento continental clásico de la no-creación judicial de las normas. ${ }^{23}$ Se estaba, de una manera técnica, sentando un criterio jurisprudencial que trascendía a todo el aparato de justicia constituido en Cuba durante aquella época.

Un análisis historiográfico más profundo podría mostrarnos ejemplos concretos de fallos y opiniones de relieve durante la época, pero de manera general se pretende en este artículo precisar el papel de este órgano de justicia y su alcance durante las dos últimas décadas de la etapa prerrevolucionaria, aunque a partir de 1952, con el golpe de Estado propinado por el dictador Fulgencio Batista, los avances formales de aquella Sala y del Tribunal mismo, quedaron suprimidos y junto con ellos, su influencia en el proceso de creación jurídica.

22 Respecto al nombre adquirido por esta Sala, García Belaúnde expone que fue adoptado literalmente de la Constitución española de 1931; aunque se denota una diferencia, porque el modelo español se denominaba Tribunal de Garantías Constitucionales, mientras que el modelo cubano mantiene igual denominación, pero agrega el término al final de "sociales", ya que éste también resolvía conflictos laborales, pudiéndonos percatar de la indudable extensión de facultades del mismo. García Belaúnde, Domingo, El Tribunal de Garantías Constitucionales y Sociales de Cuba (1940-1952), La Habana, s. e., 1996, p. 294.

23 Un profundo análisis sobre el impacto de la jurisdicción constitucional y su papel en la creación del derecho en Lafuente Balle, José Ma., La judicialización de la interpretación constitucional, Madrid, Colex, 2000.

D. R. (C) 2014. UNAM, Instituto de Investigaciones Jurídicas,

Boletín Mexicano de Derecho Comparado, núm. 139, pp. 251-283. 
Esta revista forma parte del acervo de la Biblioteca Jurídica Virtual del Instituto de Investigaciones Jurídicas de la UNAM

\section{Las expresiones de la creación judicial del derecho en la etapa revolucionaria}

Al triunfo de la Revolución en enero de 1959 tenía aún plena vigencia un importante grupo de normas heredadas de la metrópoli española.

El gobierno revolucionario no acometió la tarea de modificar aceleradamente esa legislación. El paso del tiempo creó las condiciones mínimas para avanzar hacia la institucionalización del país.

Pero los cambios efectuados dentro de las legislaciones vigentes en esta etapa no fueron del todo positivos, por decirlo de algún modo. Una de las deficiencias de marcada importancia fue la omisión en el nuevo Código Civil de las fuentes del derecho. Lo mismo sucedió en el nuevo texto constitucional, si bien la marcada influencia de las Constituciones este-europeas, de alguna manera lo justificaba.

Puede decirse que la opinión imperante durante este periodo era la de incluir a la jurisprudencia entre el grupo de fuentes, permeada de una condición indirecta; línea de pensamiento similar a la que se sostenía antes de 1959. Es en definitiva fuente indirecta del derecho, en ausencia de precepto legal aplicable. ${ }^{24}$

A partir de 1970 se produjeron acontecimientos jurídicos dentro del ordenamiento cubano que propiciaron un vuelco total a la aceptación de la jurisprudencia dentro del sistema de fuentes, desde los puntos de vista teórico y práctico.

Un elemento que no puede perderse de vista es la institucionalización definitiva de las estructuras estatales, las cuales gravitan alrededor de la unidad de poder como principio básico de estructura y funcionamiento de los Estados que integraban la comunidad socialista de entonces; lo que llevaba implícita la lógica intención (concretada luego en la Constitución de 1976) de crear un órgano supremo que sería la expresión de la concentración y centralización del poder del Estado: la Asamblea Nacional del

24 Garcini Guerra, Héctor y Reyes, Miguel, Manual de derecho administrativo. Parte general, Universidad de la Habana, 1963, t. I, pp. 25 y 26. Estos autores iniciaron su análisis precisando que la "aplicación del derecho por los tribunales a los casos que a su consideración se someten, puede en ocasiones, alcanzar el rango de creación jurídica. Ello no ocurre cuando los tribunales se limitan a aplicar la ley o a interpretarla vinculando a una de las varias soluciones lícitas que la ley ofrece a un hecho concreto. Puede sí tener carácter de fuente cuando en ausencia de toda otra forma jurídica, los tribunales, que no pueden dejar de emitir una decisión, aplican principios generales del derecho".

D. R. C 2014. UNAM, Instituto de Investigaciones Jurídicas, Boletín Mexicano de Derecho Comparado, núm. 139, pp. 251-283. 
Esta revista forma parte del acervo de la Biblioteca Jurídica Virtual del Instituto de Investigaciones Jurídicas de la UNAM

Poder Popular, representada por el Consejo de Estado entre uno y otro periodo de sesiones.

Uno de los primeros pasos legislativos que se dieron, y que sentaría las bases para acciones normativas posteriores más contundentes, puede ubicarse en la Ley núm. 1250, Ley de Organización del Sistema Judicial, de 23 de junio de 1973. Este cuerpo legal introdujo a favor del Tribunal Supremo una verdadera y expresa potestad normativa; el artículo 32 refrendaba en su inciso d) que correspondía al Consejo de Gobierno del Tribunal Supremo Popular recoger las experiencias de la actividad judicial a fin de dictar las instrucciones de carácter obligatorio que establecieran una política judicial uniforme en la interpretación y aplicación de la ley.

Así redactado el precepto, se le otorga al máximo órgano jurisdiccional cubano una potestas normandi que pasa a ser el centro reconocido directamente por el ordenamiento positivo de la acción judicial uniformadora de interpretaciones legales y de criterios de aplicación de las leyes, lo cual, reforzado por el carácter obligatorio de esas instrucciones, fue en detrimento del papel desempeñado por la doctrina legal a través del recurso de casación.

Esta nueva situación introducida por el artículo 32 de la Ley núm. 1250 de 1973 fue acogida luego por el artículo 642, inciso a), de la Ley núm. 1261 de 1974, Ley de Procedimiento Civil y Administrativo, como causal del recurso de casación y consagrado definitivamente en el artículo 124, párrafo segundo, de la Constitución de $1976 .{ }^{25}$

En igual sentido, esa potestad normativa del Tribunal Supremo Popular se ha mantenido presente en todas las leyes ulteriores referentes a la organización de nuestros tribunales, ${ }^{26}$ incluida la vigente Ley núm. 82

25 El artículo 124 de la Constitución de 1976 plantea: "El Tribunal Supremo Popular ejerce la máxima autoridad judicial y sus decisiones en este orden son definitivas. A través de su Consejo de Gobierno ejerce la iniciativa legislativa y la potestad reglamentaria; toma decisiones y dicta normas de obligado cumplimiento por todos los tribunales populares y, sobre la base de la experiencia de éstos, imparte instrucciones de carácter obligatorio para establecer una práctica judicial uniforme en la interpretación y aplicación de la ley".

26 La Ley núm. 1250 fue derogada por la Ley núm. 4 de 10 de agosto de 1977, Ley de Organización del Sistema Judicial, y ésta, a su vez, por la Ley núm. 70 de 12 de julio de 1990, Ley de los Tribunales Populares. En todos los casos existen preceptos que aluden a las funciones del Tribunal y su Consejo de Gobierno relacionadas con el tema abordado en este estudio.

D. R. (C) 2014. UNAM, Instituto de Investigaciones Jurídicas,

Boletin Mexicano de Derecho Comparado, núm. 139, pp. 251-283. 
Esta revista forma parte del acervo de la Biblioteca Jurídica Virtual del Instituto de Investigaciones Jurídicas de la UNAM

de los Tribunales Populares; ${ }^{27}$ asimismo continuó inmutable en la letra del texto resultante de la reforma constitucional de 1992 (sólo varió el número del artículo y, dentro de éste, la ubicación del párrafo donde se recoge) y de la modificación constitucional del $2002^{28}$ y también tuvo continuidad en la actual Ley núm. 7 de 1977, Ley de Procedimiento Civil, Administrativo, Laboral y Económico, entre los motivos del recurso de casación que señala el artículo 630.

Sin duda alguna, el punto más importante dentro del ordenamiento positivo nacional con respecto a la consideración de la jurisprudencia como fuente del derecho cubano lo representó la Ley núm. 1261 de enero de 1974, Ley de Procedimiento Civil y Administrativo. Con ella se produjo la reforma de los procesos civil y contencioso-administrativo, dejando sin efecto los antiguos cuerpos normativos.

En su título IV aparece el artículo 642, inciso a), por el cual procede el recurso de casación, entre otras causas porque la sentencia o resolución contenga infracción por falta de aplicación, interpretación errónea o aplicación indebida, con trascendencia al fallo, de las leyes, de las instrucciones de carácter obligatorio dictadas por el Consejo de Gobierno del Tribunal Supremo Popular, recogiendo la experiencia de la actividad judicial en la interpretación y aplicación de las leyes, o de las decisiones del propio Consejo al evacuar consultas de los tribunales sobre conflictos entre las leyes y otras disposiciones de rango normativo inferior.

Con la Ley de Procedimiento Givil y Administrativo de 1974 deja de existir el recurso de casación por infracción de doctrina legal, el que viene a ser sustituido por una nueva causal: la infracción de instrucción, dictamen o

27 La vigente Ley núm. 82 de 11 de julio de 1997, Ley de los Tribunales Populares, dejó sin efectos a la anterior Ley núm. 70 de 12 de julio de 1990, manteniendo viva en toda su extensión la mencionada novedad introducida por la Ley núm. 4, ahora en los artículos 15, apartado 2, y 19, apartado 1, inciso h).

28 El artículo 121 de la Constitución establece: "Los tribunales constituyen un sistema de órganos estatales, estructurado con independencia funcional de cualquier otro y subordinado jerárquicamente a la Asamblea Nacional del Poder Popular y al Consejo de Estado.

El Tribunal Supremo Popular ejerce la máxima autoridad judicial y sus decisiones, en este orden, son definitivas. A través de su Consejo de Gobierno ejerce la iniciativa legislativa y la potestad reglamentaria; toma decisiones y dicta normas de obligado cumplimiento por todos los tribunales populares y, sobre la base de la experiencia de éstos, imparte instrucciones de carácter obligatorio para establecer una práctica judicial uniforme en la interpretación y aplicación de la ley".

D. R. (C) 2014. UNAM, Instituto de Investigaciones Jurídicas, Boletín Mexicano de Derecho Comparado, núm. 139, pp. 251-283. 
Esta revista forma parte del acervo de la Biblioteca Jurídica Virtual del Instituto de Investigaciones Jurídicas de la UNAM

acuerdo del Pleno del Tribunal Supremo Popular o su Consejo de Gobierno.

Puede decirse que de enunciar el posible valor de la jurisprudencia como fuente del derecho cubano se pasa, desde 1974, a desconocerla totalmente como fuente, incluso negándole su valor indirecto; no se le reconoce como tal ni siquiera de hecho o como mecanismo de integración del derecho ante vacíos normativos o normas imprecisas o ambiguas, hecho comprobado con la promulgación del nuevo Código Civil cubano, en 1987.

Posteriormente, los cambios jurídicos en Cuba tuvieron como imprescindible punto de partida la reforma constitucional de 1992, que por lo demás no provocó ninguna mutación en la potestad normativa que se le reconocía constitucionalmente desde 1976 al Tribunal Supremo Popular, ni se variaron esos planteamientos en los cuerpos normativos involucrados en ello; por ende, la situación referente a la jurisprudencia continuó invariable.

Sin embargo, las transformaciones iniciaron un proceso dentro del sistema jurídico que se caracteriza por relativizar varias de las ideas teóricas y prácticas sobre el tema.

Con independencia de que no ha habido en este tiempo modificación sustancial alguna en las bases positivas que sustentan la opinión preponderante de excluir a la jurisprudencia como fuente del derecho cubano, lentamente se ha venido operando cierta matización en los planteamientos acerca del valor de ésta como fuente del derecho. Esto ha favorecido un importante debate, del cual desarrollaremos algunos ejemplos.

\section{POLÉMICAS RESPECTO AL RECONOCIMIENTO DE LA JURISPRUDENCIA COMO FUENTE FORMAL DE DEREGHO EN GUBA}

Sin duda alguna, el reconocimiento o no de la jurisprudencia como fuente formal dentro del ordenamiento jurídico cubano, ha creado una de las más atractivas y controvertidas polémicas en el ámbito jurídico cubano.

Debe destacarse el punto de vista dado por Fernando Álvarez Tabío durante los años setenta del pasado siglo: 
Esta revista forma parte del acervo de la Biblioteca Jurídica Virtual del Instituto de Investigaciones Jurídicas de la UNAM

Es bueno señalar que el Tribunal Supremo Popular también se convierte en órgano creador de jurisprudencia, pero no mediante la casación, sino sobre la base de la experiencia judicial, pues es a su Consejo de Gobierno a quien corresponde la potestad de dictar instrucciones de carácter obligatorio para todos los tribunales con el fin de establecer una práctica judicial uniforme en la interpretación y aplicación de la ley. Dichas interpretaciones se convierten en juicios de derecho, de rango equivalente a la norma legal, cuya contradicción, oscuridad u omisión viene a subsanar. ${ }^{29}$

Álvarez Tabío muestra, en cierta medida, una fisura en la unidad de criterio existente que rechazaba de forma absoluta a la jurisprudencia como fuente del derecho. En sus planteamientos da cabida a la creación de jurisprudencia, pero no a partir de los fallos reiterados de ese órgano, sino a raíz de las instrucciones que emanan de su Consejo de Gobierno. Para este autor, el máximo órgano judicial cubano sienta jurisprudencia por la vía de las instrucciones que dicta el Consejo de Gobierno, las que tienen un carácter obligatorio. La esencia de sus palabras radica en que va al fondo del fenómeno (regla de derecho creada por el Tribunal superior de justicia sobre la base de su actividad jurisdiccional) y no sólo a la forma (que adquiere la figura de la instrucción, el dictamen o el acuerdo como vehículos jurídicos de instrumentación dispositiva). ${ }^{30}$

Posiciones totalmente contrarias a ésta las encontramos en las opiniones de dos reconocidos autores: Cañizares Abeledo y Grillo Longoria. Para el primero: "La jurisprudencia como fuente de derecho es inadmisible dentro del sistema jurídico socialista, por cuanto en un régimen de estricta legalidad como éste, tanto los órganos judiciales como los administrativos deben aplicar el derecho y no crearlo". ${ }^{31}$

Por su parte, Grillo Longoria tampoco aceptaba a la jurisprudencia porque:

... ello significaría otorgarle a los tribunales una función legislativa que no les concierne, por corresponder exclusivamente a los órganos creados por el Estado para ese fin. Además, la justicia socialista exige que se tengan en cuenta las particularidades de cada caso, y la llamada jurisprudencia o doctrina

29 Álvarez Tabío, Fernando, El recurso de inconstitucionalidad, cit., p. 383.

30 Véase Mendoza Díaz, Juan et al., Lecciones de derecho procesal civil, La Habana, Editorial Félix Varela, 2001, p. 6.

31 Cañizares Abeledo, Fernando, op. cit., p. 80.

D. R. (C) 2014. UNAM, Instituto de Investigaciones Jurídicas, Boletín Mexicano de Derecho Comparado, núm. 139, pp. 251-283. 
Esta revista forma parte del acervo de la Biblioteca Jurídica Virtual del Instituto de Investigaciones Jurídicas de la UNAM

legal crea la tendencia a resolver en la misma forma casos que, analizados con profundidad, teniendo en cuenta las especificidades, merecen soluciones distintas. ${ }^{32}$

El fundamento en el cual Grillo Longoria basa su criterio es que para él la interpretación de las leyes no establece nuevas normas jurídicas sino que se limita a aclarar el verdadero sentido y alcance de las normas vigentes ${ }^{33}$ y por eso no pueden ser considerados los acuerdos del Consejo de Gobierno del Tribunal Supremo como fuentes formales del derecho, ya que su función es meramente interpretativa y no normativa.

Estas consideraciones de los autores nacionales estuvieron bajo la influencia directa de la práctica jurídica de la extinta Unión de Repúblicas Socialistas Soviéticas (URSS). ${ }^{34}$ Es por ello que podemos encontrar planteamientos básicos como los de Zhidkov, Chirkin y Yudin:

En el derecho socialista no se conocen, por ejemplo, fuentes tales como el precedente judicial o el administrativo, que en varios Estados burgueses desempeñan un relevante papel. El precedente judicial, como evidencia la práctica de su aplicación en dichos Estados, puede abrir extensos espacios para la arbitrariedad judicial, minando de esa manera el principio de la legalidad. En los Estados socialistas, los órganos judiciales, al administrar la justicia, se apoyan en las leyes y los actos normativos-jurídicos derivados de ella. Cuando se juzgan causas concretas, el tribunal aplica normas jurídicas, no las crea. $^{35}$

En igual sentido Mánov expone que: "Otorgar la condición de fuente de derecho al precedente judicial y a la práctica judicial significa, en esencia, la transmisión de funciones de creación de normas

32 Grillo Longoria, Rafael, Derecho procesal civil. Teoría general del proceso civil, La Habana, Editorial Pueblo y Educación, 1993, t. I, p. 17.

33 Idem.

34 No obstante, estas posiciones fueron cediendo y la jurisprudencia en la extinta URSS, asumiendo otro rol, véase David, René y Jauffret-Spinosi, Camille, Los grandes sistemas jurídicos contemporáneos, 11 a. ed., México, Universidad Autónoma de México, 2010, p. 160 .

35 Zhidkov, O. et al., Fundamentos de la teoría socialista del Estado y el derecho, Moscú, Progreso, 1980, pp. 334 y 335 .

D. R. (C) 2014. UNAM, Instituto de Investigaciones Jurídicas,

Boletín Mexicano de Derecho Comparado, núm. 139, pp. 251-283. 
Esta revista forma parte del acervo de la Biblioteca Jurídica Virtual del Instituto de Investigaciones Jurídicas de la UNAM

a los órganos judiciales. Esa situación es impermisible en los Estados socialistas". ${ }^{36}$

Por su parte, Pérez Gallardo está totalmente de acuerdo con la no existencia de la jurisprudencia. Así, a la par de negar con rotundidad ésta como fuente, apunta:

Los criterios jurisprudenciales no tienden a ser inmutables, no lo pueden ser. La dinámica de las relaciones sociales impone que el juez sea flexible y que sea capaz de interpretar las normas legales conforme con el momento histórico en que se aplican, lo cual no es sino un corolario de la esencia misma de la función jurídica interpretativa, que consiste en poner las normas en relación con la vida, para que su concreción, en el caso enjuiciado, resulte justa. ${ }^{37}$

Como expresa el profesor Albaladejo, "no va a ser el Tribunal Supremo lo único del país insensible a las alteraciones de la vida y de su entorno". ${ }^{38}$

El profesor Fernández Bulté acotaba que nuestro sistema jurídico no admite la fuerza vinculante de las sentencias dictadas por ningún tribunal, incluido el Supremo, con lo cual ha desaparecido la jurisprudencia o la interpretación jurisprudencial como fuente de derecho. ${ }^{39}$

Planteamientos en un sentido contrario, comenzamos a apreciar con más fuerza entre algunos académicos cubanos, fundamentalmente en las últimas décadas.

La opinión de Matilla Correa resulta muy importante:

Está demostrado que dentro del entramado de disposiciones nacionales no existe ningún precepto jurídico que le asigne a la jurisprudencia, per se, efectos vinculantes inmediatos como norma jurídica en el plano nacional. Sin embargo, el hecho de considerar que la misma carece de fuerza formal, directa o inmediata, no debe (ni puede) conducirnos (con un saldo negativo absoluto) a cerrar el análisis sobre su presencia dentro del conjunto de fuentes

36 Mánov, A. et al., Teoría marxista del Estado y del derecho, La Habana, Editorial de Ciencias Sociales, 1981, p. 580.

37 Véase Vallet de Goytisolo, Juan B., Metodología de la determinación del derecho II (parte sistemática), Madrid, Centro de Estudios Ramón Areces-Consejo General del Notariado, 1996, p. 1412.

38 Albaladejo García, Manuel, "El cambio de jurisprudencia", Anales de la Real Academia de Furisprudencia y Legislación (separata), núm 28, s. p. i., p. 19.

39 Fernández Bulté, Julio, op. cit., p.112.

D. R. C 2014. UNAM, Instituto de Investigaciones Jurídicas, Boletín Mexicano de Derecho Comparado, núm. 139, pp. 251-283. 
Esta revista forma parte del acervo de la Biblioteca Jurídica Virtual del Instituto de Investigaciones Jurídicas de la UNAM

jurídico-administrativas, pues sería asumir una visión poco realista o material y sí muy formalista y limitada. ${ }^{40}$

Para ilustrar su tesis destaca algunas similitudes entre la jurisprudencia (vista genéricamente) y las instrucciones emanadas del Consejo de Gobierno del Tribunal Supremo Popular:

- la jurisprudencia es sentada por el tribunal de mayor rango jerárquico en la estructura judicial; en Cuba, las instrucciones a que nos estamos refiriendo son dictadas por el Tribunal Supremo, por conducto de su Consejo de Gobierno;

- la jurisprudencia se forma a partir de los criterios de derecho contenidos en las sentencias judiciales; en Cuba, como bien refrenda la Constitución y la Ley de los Tribunales Populares, las instrucciones del Consejo de Gobierno del Tribunal Supremo Popular tienen como base la experiencia de los tribunales, y dicha experiencia proviene (de dónde si no) de la manera en que los últimos resuelven las situaciones que les han sido sometidas a su conocimiento, y está contenida en las sentencias que emiten; las instrucciones se convierten así en un vehículo de recogida e instrumentación de los criterios que siguen los tribunales en su actividad y que encuentran contenidos en sus fallos;

- la jurisprudencia tiene entre sus funciones la de producir una unidad de criterio en la aplicación e interpretación del derecho por los tribunales; entre nosotros, las instrucciones del Consejo de Gobierno del Tribunal Supremo Popular (según prescripción constitucional y legal) buscan establecer una práctica judicial uniforme en la interpretación y aplicación de la ley;

- una vez sentada la jurisprudencia es de obligatoria observancia para los tribunales de menor rango; en nuestro país (como se regula en el ordenamiento positivo), las instrucciones del Consejo de Gobierno del Tribunal Supremo Popular tienen carácter obligatorio para los órganos inferiores;

— la infracción de la jurisprudencia puede dar origen a un recurso de casación; en el plano nacional la infracción de las instrucciones de carácter obligatorio dictadas por el Pleno del Tribunal Supremo Popular o su Con-

40 Matilla Correa, Andry, Temas..., cit., p. 98. Continúa en esta misma línea expresando: "la jurisprudencia es fuente indirecta (porque a través de las instrucciones del Consejo de Gobierno del Tribunal Supremo Popular se le da carácter obligatorio a las reglas extraídas de las sentencias de los órganos judiciales nacionales, en especial de ese órgano supremo) y fuente material (porque aporta la sustancia de las tantas veces aludidas instrucciones) del sistema de derecho cubano en general y del derecho administrativo cubano en particular, para los casos en que la misma sea de contenido jurídico-administrativo."

D. R. (C) 2014. UNAM, Instituto de Investigaciones Jurídicas,

Boletín Mexicano de Derecho Comparado, núm. 139, pp. 251-283. 
Esta revista forma parte del acervo de la Biblioteca Jurídica Virtual del Instituto de Investigaciones Jurídicas de la UNAM

sejo de Gobierno se recoge por la Ley de Procedimiento Civil, Administrativo, Laboral y Económico cubana como causal del recurso de casación. ${ }^{41}$

\section{Para la profesora Prieto Valdés:}

El lugar de la jurisprudencia en el ordenamiento debe ser supletorio respecto al acto normativo, aun cuando posee la fuerza jurídica que le permite que los jueces ante su desconocimiento sean objeto de correcciones disciplinarias, o removidos por su incumplimiento reiterado, lo cual se refuerza en las materias civil, administrativo y laboral al establecerse por la Ley de Procedimiento que su inobservancia es causal de casación. En materia penal, si bien es cierto que la Ley de Procedimiento no reconoce tales decisiones como obligatorias específicamente, en la práctica deben ser observadas conforme a la previsión constitucional y legal antes expuesta. ${ }^{42}$

\section{Mendoza Díaz acota:}

La situación que presentamos en cuanto a la importancia de las decisiones del Consejo de Gobierno del Tribunal Supremo, se asienta históricamente en el valor concedido a la jurisprudencia dentro del sistema de fuentes formales del derecho español; aspectos que de primera impresión pueden parecer que no están relacionados. ${ }^{43}$

Dentro de su investigación, este profesor realiza un detallado análisis de las atribuciones concedidas a dicho órgano. Además del artículo 121 constitucional, insiste en el artículo 630.1 de la Ley de Procedimiento Civil, Administrativo, Laboral y Económico, ${ }^{44}$ artículo que, en su criterio "ha elevado a la categoría de fuentes formales del ordenamiento civil en

41 Ibidem, pp. 99 y 100.

42 Prieto Valdés, Martha, op. cit., p. 89.

43 Mendoza Díaz, Juan et al., op. cit., p.11.

44 "Artículo 630. Procede el recurso de casación por los motivos siguientes:

1.- Que la sentencia o resolución contenga infracción por falta de aplicación, interpretación errónea o aplicación indebida, con trascendencia al fallo, de las leyes, de las interpretaciones de éstas emanadas del Consejo de Estado, de las instrucciones de carácter obligatorio dictadas por el Pleno del Tribunal Supremo Popular o su Consejo de Gobierno, recogiendo la experiencia de la actividad judicial en la interpretación y aplicación de las leyes, o de las decisiones dictadas por esos órganos al evacuar consultas de los tribunales sobre conflictos entre leyes y otras disposiciones de rango normativo inferior".

D. R. C 2014. UNAM, Instituto de Investigaciones Jurídicas, Boletín Mexicano de Derecho Comparado, núm. 139, pp. 251-283. 
Esta revista forma parte del acervo de la Biblioteca Jurídica Virtual del Instituto de Investigaciones Jurídicas de la UNAM

general, y del derecho procesal, en particular, los criterios interpretativos... del Consejo de Gobierno del Tribunal Supremo", ${ }^{45}$ constituyendo éste un elemento de análisis esencial en el presente estudio.

Existen posiciones doctrinales que aceptan la jurisprudencia como fuente de derecho en el ordenamiento jurídico cubano, pero desde otros ángulos, considerando necesario destacar el criterio de Rodríguez Sánchez, quien opina que la existencia jurisprudencial debe ser vista como un método de creación del derecho. En tal sentido expone:

Estoy de acuerdo, en principio, que sea la ley la máxima expresión de fuente de derecho y que el juez debe limitarse a aplicar lo que ella contiene pero... no podemos negar el importante papel que desempeña la jurisprudencia en la solución de casos, pues en la aplicación del derecho se presentan situaciones en las que resulta necesario aclarar lagunas que presenta la ley, lo cual no puede ser posible mediante los métodos de interpretación conocidos y es en ese momento en el que podría otorgársele al juez algún margen de creatividad. $^{46}$

Las múltiples referencias reproducidas en este apartado resultan necesarias e insoslayables para evaluar el estado de este debate, a fin de fijar puntos de partida en los análisis y las conclusiones posteriores.

\section{MANiFESTAGIONES DE LA JURISPRUDENCIA EN EL CONTEXTO NORMATIVO Y EN LA LABOR JUDICIAL EN CUBA. PAPEL DEL TRIBUNAL SUPREMO DE JUSTICIA Y SU CONSEJO DE GOBIERNO}

A través de los años, la labor del Tribunal Supremo Popular ha sido intensa y las manifestaciones de la jurisprudencia en el contexto normativo y la actuación judicial son amplias, independientemente de su no reconocimiento formal, al menos como fuente generadora de derecho.

Desde las dos aristas antes mencionadas, es decir, como reiteración de los fallos y formalización de las decisiones del Consejo de Gobierno

45 Mendoza Díaz, Juan et al., op. cit., p.18.

46 Rodríguez Sánchez, Ciro Félix, "La jurisprudencia como fuente complementaria del derecho", Revista IV Conferencia Científica sobre el Derecho. Santiago de Cuba, Cuba, Barquito de Papel, 1997, p. 60.

D. R. (C) 2014. UNAM, Instituto de Investigaciones Jurídicas,

Boletín Mexicano de Derecho Comparado, núm. 139, pp. 251-283. 
Esta revista forma parte del acervo de la Biblioteca Jurídica Virtual del Instituto de Investigaciones Jurídicas de la UNAM

en instrumentos jurídicos que se traducen en acuerdos, instrucciones, dictámenes, entre otros, los ejemplos son muchos. La proyección interna, que es el primero de los casos, y la externa, que es el segundo, han servido de base para demostrar la tendencia actual del reconocimiento de la jurisprudencia en el ordenamiento jurídico cubano en estos tiempos.

En consecuencia, se plantea en el presente apartado una selección de algunos de los fallos, así como otras disposiciones internas del máximo órgano de justicia, que sostienen algunos puntos de este ensayo acerca de la formación de la jurisprudencia y su papel en la creación del derecho. Esta muestra es aleatoria y comprende algunos instrumentos elaborados en la última década, en su mayoría.

Sentencia núm. 472 de 10 de mayo de 2002, de la Sala de lo Civil y lo Administrativo del Tribunal Supremo Popular

... como reiteradamente ha sostenido esta Sala Suprema de Justicia, la calidad de propietario lleva implícita la posesión del bien de que se trate y el hecho de no residir en la vivienda no invalida el ejercicio de la acción para la aplicación del citado artículo 73 [de la Ley General de la Vivienda].

Sentencia núm. 293 de 15 de enero de 2004, de la Sala de lo Penal del Tribunal Supremo Popular

... en reiteradas sentencias esta Sala ha declarado que no todas las acciones antijurídicas caen bajo la sanción de la Ley Penal, ni es lícito interpretarla extensivamente para ser aplicables sus disposiciones a casos que no estén claros y expresamente determinados entre los que son objeto de sanción penal.

Sentencia núm. 3134 de 4 de septiembre de 2006 de la Sala de lo Penal del Tribunal Supremo Popular.

... que es criterio casi unánime en la doctrina, y refrendado reiteradamente por esta Sala en sus sentencias, que las pruebas que resulten pertinentes y son admitidas por el Tribunal en el momento procesal oportuno deben ser practicadas en el juicio oral y habiéndose propuesto por el letrado defensor del acusado en el trámite de calificación y proposición de pruebas y admitido por el Tribunal en el auto correspondiente, el examen de los seis testigos propuesto por el fiscal y además otros tres propuestos únicamente por esta parte. 
Esta revista forma parte del acervo de la Biblioteca Jurídica Virtual del Instituto de Investigaciones Jurídicas de la UNAM

Sentencia núm. 4240 de 8 de diciembre de 2009 de la Sala de lo Penal del Tribunal Supremo Popular. "Que es doctrina reiterada de este máximo órgano de justicia, que en el caso del delito de portación y tenencia ilegal de armas o explosivos que prevé el artículo doscientos once en su apartado uno del Código Penal, debe calificarse de manera independiente...".

Estos elementos resaltados nos permiten observar cómo los criterios de Sala son asumidos como referentes, como muestra de una de las manifestaciones jurisprudenciales, más cercana incluso a la doctrina jurisprudencial descrita por varios autores. ${ }^{47}$

Dictamen núm. 307, por Acuerdo núm. 85 del Consejo de Gobierno del Tribunal Supremo Popular (GGTSP), 23 de diciembre de 1989. ${ }^{48}$ Éste es uno de los dictámenes más emblemáticos y que con mayor frecuencia es utilizado como ejemplo, en cuanto a la interpretación y solución de tipos penales, al punto de ser entendido por algunos como una pauta típica de una norma jurídica. Se sintetizan en esta oportunidad los puntos de la consulta realizada por el fiscal general y la opinión del supremo órgano:

Consulta: "Cuando en un caso determinado se den ambos presupuestos, es decir, el sacrificio y la venta por un mismo acusado [en relación a los delitos de Sacrificio Ilegal de Ganado Mayor y Venta de sus Carnes del artículo 240.1 y 2o. del Código Penal]:

"DDebemos considerar que estamos en presencia de dos hechos independientes uno del otro y, por tanto, con sanciones para cada hecho?"

Dictamen del CGTSP: “... se concluye que el Sacrificio Ilegal de Ganado Mayor, la Venta, Transporte y Comercialización de sus Carnes, aunque acontezca en un mismo sujeto de la relación jurídica-procesal y se hayan realizado sucesivamente, están unidos por conexidad procesal, de acuerdo con el artículo 13, acápite 5), de la Ley de Procedimiento Penal, resultando innegable que cada uno de estos hechos originan delitos independientes entre sí, sin relación necesaria y, son, por tanto, sancionados individualmente como tipos delictivos separados del Sacrificio Ilegal”.

47 Un acercamiento a la distinción - necesaria - entre doctrina legal y doctrina jurisprudencial, véase Vallet de Goytisolo, Juan, "El razonamiento judicial", Anales de la Real Academia de Furisprudencia y Legislación, Madrid, Dykinson, núm. 39, 2009, pp. 19-32.

48 No obstante, debe aclararse que el mencionado Dictamen fue derogado por el Acuerdo 240 de 1999, del CGTSP, el que suprimió las ataduras para que las salas de justicia apliquen correctamente la conexidad sustantiva, cuando adviertan que está presente. El valor de este Dictamen es de carácter histórico, por eso se incluye como referencia.

D. R. C 2014. UNAM, Instituto de Investigaciones Jurídicas,

Boletín Mexicano de Derecho Comparado, núm. 139, pp. 251-283. 
Esta revista forma parte del acervo de la Biblioteca Jurídica Virtual del Instituto de Investigaciones Jurídicas de la UNAM

La conclusión más importante que puede derivarse de este ejemplo, radica en el hecho de que, en efecto, no existe en el derecho positivo, en la norma penal sustantiva, una solución directa a esta situación; solución que ha venido a crear el juez (como decisión colectiva de un órgano de gobierno del más alto tribunal de justicia), cuya función rectora concuerda perfectamente con el alcance de una nueva norma de derecho. Si hasta ese momento, como se señala en la consulta del fiscal general, existían "criterios distintos al respecto" sobre cómo calificar este delito al concurrir los elementos fácticos narrados, éstos han de ceder al juicio realizado por el CGTSP. Se ha creado una regla, que debe ser observada por el resto de los tribunales, pero que también determina la actuación posterior incluso de la Fiscalía, en el ejercicio de su acción punitiva. El juicio que se sostiene en el presente artículo es que esta decisión sobrepasa los límites de la interpretación, para configurar una regla de actuación nueva, cuya inobservancia genera consecuencias jurídicas (por ejemplo, la posible casación de la sentencia).

Dictamen núm. 411, por Acuerdo núm. 206 del Consejo de Gobierno del Tribunal Supremo Popular (CGTSP), 8 de noviembre de 2001. Éste es un interesante dictamen que viene a resolver una consulta en los términos de la vigencia temporal del derecho, realizada a título del fiscal general.

Consulta: "Se ha suscitado duda relativa al pronunciamiento que deberá hacerse sobre calificación legal de los delitos, cuando los hechos imputados constituyen un delito de carácter continuado, pero los actos individuales que conforman la narración total del hecho cometido por el mismo acusado, ocurrieron bajo el imperio de leyes diferentes, por haberse producido cambios legislativos".

\section{Dictamen del CGTSP:}

... atendiendo a la excepcionalidad y temporalidad del caso en consulta, así como al principio de equidad y de justicia que prima en nuestro ordenamiento penal, en los casos de delitos de carácter continuado, cuya acción ilícita original comenzó en vigor de una ley más favorable, y se continuó la conducta, como resolución criminal, estando en vigencia otra ley penal más severa, deberá el tribunal juzgador romper la construcción ficticia de la continuidad, al momento de entrar en vigor la nueva ley, aplicar la institución del delito continuado y sancionar los hechos por cada una de las leyes vigentes al mo- 
Esta revista forma parte del acervo de la Biblioteca Jurídica Virtual del Instituto de Investigaciones Jurídicas de la UNAM

mento de su comisión, haciendo uso posteriormente de la sanción conjunta para fijar definitivamente la individualizada y proporcional pena a que sea acreedor el sancionado.

La solución de este supuesto no puede encontrarse en la norma penal sustantiva. Es una circunstancia no prevista por el derecho positivo, en la cual ha debido intervenir el CGTSP para trazar una pauta interpretativa, que realmente lo que está determinando es la existencia de una nueva regla de actuación para el resto de los tribunales, y un criterio orientador para la posterior calificación adecuada (desde la actuación fiscal). Si bien la legislación penal, incluida la procesal, hacen referencia a los principios y soluciones relacionadas con la vigencia temporal del derecho, encuentra un vacío ante un caso como el narrado (no debe justificarse esta omisión sobre la base del excesivo casuismo de la norma jurídica), que viene a ser suplido con un criterio jurisdiccional que sirve de directriz, de regla para las actuaciones futuras. No debe obviarse en este dictamen la referencia a principios generales del derecho, una fuente tampoco reconocida en nuestro ordenamiento jurídico.

\section{POSIBLES CONSECUENCIAS DEL RECONOCIMIENTO}

DE LA JURISPRUDENCIA COMO FUENTE DEL DERECHO EN EL ORDENAMIENTO JURÍDICO GUBANO

Corresponde en este apartado enumerar algunas de las posibles consecuencias que se han determinado, a partir del desarrollo de la investigación, respecto al reconocimiento de la jurisprudencia dentro del sistema de fuentes del derecho en Cuba.

En un primer momento debe significarse el valor de este reconocimiento para el funcionamiento sistémico y armónico del ordenamiento jurídico. Teniendo en cuenta la definición de este último como conjunto de disposiciones normativas, principios y presunciones vigentes en un territorio determinado, puede apreciarse el necesario desarrollo sistémico de sus elementos integrantes.

En tal sentido, la visión existente de reducir a una fuente formal única y válida para la solución de los conflictos o la regulación de las relaciones sociales que trascienden a la tutela estatal (relaciones jurídicas), dificulta de alguna manera este carácter sistémico. 
Esta revista forma parte del acervo de la Biblioteca Jurídica Virtual del Instituto de Investigaciones Jurídicas de la UNAM

Así, ampliar el número de fuentes, principalmente las formales, entre las que se sitúa la jurisprudencia, pudiera favorecer el funcionamiento más armónico y, en un estricto sentido de sistema, del ordenamiento jurídico cubano. Al mismo tiempo, desde el propio papel de la jurisprudencia en el proceso de uniformidad interpretativa, coadyuvaría a perfeccionar el proceso de interpretación que debe anteceder al de aplicación del derecho, alcanzándose un grado superior en la eficacia normativa y, por ende, en la capacidad del ordenamiento de brindar soluciones efectivas a las disímiles situaciones que en el contexto social resulten susceptibles de ser establecidas por el derecho.

En segundo lugar, el reconocimiento formal de la actividad creadora de derecho por parte del máximo órgano de justicia de nuestro país y su importancia en el proceso de uniformidad de la interpretación normativa, a través de las manifestaciones de la jurisprudencia anteriormente expuestas, constituye un elemento esencial que se desprende de este análisis.

En correspondencia con el estudio realizado respecto a las fuentes formales del derecho en Cuba y los órganos facultados para crear derecho, se considera oportuno y pertinente volver sobre el papel del Consejo de Gobierno del Tribunal Supremo Popular.

Este órgano tiene un doble carácter: es de ordinario, como cualquier otro órgano judicial, intérprete de la ley y, a la vez, se le reconoce esa facultad con carácter especial por cuanto tiene la atribución de establecer una interpretación y práctica judicial uniforme en el país mediante instrucciones obligatorias.

El Consejo de Gobierno, amparado constitucionalmente, goza de amplias facultades: aclaración de las normas en caso de dudas; adecuación de normas y procedimientos ante cambios sustantivos esenciales que no han previsto los primeros; suple vacíos normativos o hace interpretaciones extensivas que surten efectos modificativos o aditivos referentes al ordenamiento jurídico o una disposición en particular, según se ha podido mostrar anteriormente.

Como es conocido, en la actualidad las interpretaciones del Consejo de Gobierno del Tribunal Supremo Popular no se contemplan como fuentes creadoras del derecho, quedando demostrado con anterioridad que en muchos casos sus decisiones son susceptibles de ser entendidas como verdaderas normas de derecho, e incluso, lo modifican e imponen un orden a seguir que puede conllevar al establecimiento del recurso de casación en caso de ser obviado. 
Esta revista forma parte del acervo de la Biblioteca Jurídica Virtual del Instituto de Investigaciones Jurídicas de la UNAM

En consecuencia, el reconocimiento efectivo de la jurisprudencia emanada de este órgano, con las implicaciones que desde el punto de vista técnico-jurídico traería para el ordenamiento jurídico cubano, contribuiría a formalizar lo que ya en la práctica ha devenido como un hecho: la capacidad creadora del máximo tribunal de justicia.

Otra de las consecuencias determinadas está relacionada con una posible definición más amplia de las fuentes del ordenamiento y su incorporación posterior a la legislación vigente (en la Constitución, preferiblemente, por su carácter ordenador).

Se trata de uno de los temas claves de este análisis, pues como se ha expuesto, nuestro ordenamiento jurídico resulta sui generis respecto a este punto al no reconocer en ningún cuerpo normativo, expresamente, las fuentes del derecho. Ni siquiera el acto normativo, si bien es la única vía para la creación normativa abordada en la Constitución, y como principio (legalidad) en nuestra legislación sustantiva y procesal.

Lo cierto es que, desde la visión misma de sistema respecto al ordenamiento jurídico cubano, se hace imprescindible superar la visión reduccionista de las fuentes del derecho en Cuba. Incorporar esta nueva manifestación de la creación del derecho sería un elemento muy favorable, que pudiera ser seguido por la apreciación futura de otras fuentes, materialmente existentes y empleadas en la solución jurídica de situaciones dadas, como la costumbre y los principios generales del derecho.

Ofrecerle este tratamiento a la jurisprudencia, con sus peculiaridades en Cuba, confirmaría la idea de ampliar el número de fuentes jurídicas formales, garantizando al mismo tiempo una noción sistémica, pálidamente reconocida en el contexto cubano.

$\mathrm{Al}$ mismo tiempo, esta incorporación de las fuentes formales debería partir desde el propio texto constitucional, debido al carácter ordenador y supremacía jurídica de la Constitución. Ante una eventual reforma, sería de gran importancia incorporar estos nuevos elementos, que contribuirían indefectiblemente a perfeccionar la estructura y funcionamiento del ordenamiento jurídico en sentido amplio.

Un hecho trascendente que pudiera generarse en relación con el reconocimiento de la jurisprudencia como fuente de derecho es la configuración 
Esta revista forma parte del acervo de la Biblioteca Jurídica Virtual del Instituto de Investigaciones Jurídicas de la UNAM

de un mecanismo de solución ante posibles vacios normativos ${ }^{49}$ (con aplicación del método de heterointegración del derecho).

Superado el dogma de la plenitud en el contexto cubano (desde la posición sostenida en este artículo, lo cual no significa que sea una postura dominante o absoluta en la doctrina, incluso nacional), se puede decir que las lagunas normativas existen en todos los ordenamientos jurídicos ${ }^{50}$ derivadas entre otras causas, del propio desfase entre la dinámica social y la normativa jurídica. Sin embargo, aunque son inevitables en el plano normativo, el propio derecho les ofrece soluciones a través de los mecanismos de integración. Éstos son la autointegración ${ }^{51}$ y la heterointegración..$^{52}$

Bobbio $^{53}$ manifiesta que la heterointegración (que para los fines de esta investigación es el método que más interesa) puede llevarse a cabo por dos vías: recurriendo a ordenamientos diversos o a fuentes diferentes de la dominante. En el primer caso, por ejemplo, recurriendo a las normas del derecho romano, derecho natural o del derecho comparado. En el segundo, a otras fuentes distintas a la ley, las que pueden tener menor jerarquía como son la costumbre, la doctrina o la jurisprudencia, la que, por otra parte, no siempre es uniforme.

49 Las lagunas o vacíos normativos son identificados como espacios carentes de regulación, situaciones para las que no se ha previsto por parte del legislador una norma jurídica (lo que se asimila, en la concepción hartiana, a la existencia de zonas de penumbra, propias de la textura abierta que caracteriza al ordenamiento jurídico). Sobre el tema, véase Ferrari Yaunner, Majela, Los principios de legalidad y seguridad jurídica como fundamentos del proceso de integración del derecho para colmar las lagunas de la ley en Cuba, tesis presentada en opción del grado científico de doctor en ciencias jurídicas, Cuba, Facultad de Derecho Universidad de La Habana, 2010, pp. 32 y 33.

50 "Es un hecho que en el conjunto de leyes, reglamentos, costumbres, precedentes jurisprudenciales, etcétera, que integran el derecho formulado de un orden jurídico, hay vacíos”. Recaséns Siches, Luis, Filosofia del derecho, México, Porrúa, 1959, p. 325.

51 Cuando los métodos de integración se encuentran en el mismo ordenamiento jurídico, éste utiliza sus propias normas o principios para solucionar las lagunas. En estos casos el sistema acude a sus propias soluciones y límites, como son la analogía, o los principios generales del derecho. Cfr. Aseff, Lucía María, La interpretación de la ley y otros textos críticos de teoría general, Argentina, Juris, 2004, p. 69; Bobbio, Norberto, Teoría general del derecho, Madrid, Debate, 1998, p. 242.

52 Utilización de los mecanismos de integración pero buscando la solución a la laguna fuera del ordenamiento jurídico.

53 Bobbio, Norberto, op. cit., pp. 242-245; véase Aseff, Lucía María, op. cit., pp. 68 y 69; e Iturralde Sesma, Victoria, Lenguaje legal y sistema jurídico. Cuestiones relativas a la aplicación de la ley, Madrid, Tecnos, 1989, p. 182.

D. R. C 2014. UNAM, Instituto de Investigaciones Jurídicas, Boletín Mexicano de Derecho Comparado, núm. 139, pp. 251-283. 
Esta revista forma parte del acervo de la Biblioteca Jurídica Virtual del Instituto de Investigaciones Jurídicas de la UNAM

El ordenamiento jurídico cubano carece de una enunciación de estos métodos. Incluso, al utilizar el Consejo de Gobierno esta facultad, sólo establecería una pauta valorativa para realizar el proceso de integración del derecho, para el cual deberá recurrir inevitablemente a algunos de estos métodos. No obstante, esta carencia de regulación del proceso de integración de las lagunas de la ley en Cuba es resultado también de la confusión terminológica y práctica entre interpretación e integración del derecho, lo que limita la adecuada realización de este proceso, teniendo en cuenta que aun cuando la primera es una herramienta básica e ineludible en la aplicación del derecho, no es suficiente para colmar las lagunas normativas.

En la actualidad los jueces cubanos, en el ejercicio de sus funciones, cuando se encuentran ante lagunas normativas son conscientes de la obligación de colmarlas. Las dificultades fundamentales se concentran en la diversidad de criterios acerca de las vías a utilizar. En este contexto, el reconocimiento de la jurisprudencia pudiera resultar una excelente arma auxiliar para enfrentar esta problemática.

Éstas, a grandes rasgos, pudieran ser las principales consecuencias derivadas del reconocimiento de la jurisprudencia como fuente formal en Cuba. Si bien es cierto que ha dominado en el pensamiento y la práctica jurídica cubana la idea de colocar en un plano secundario la actividad judicial como fuente generadora del derecho (por no asumir absolutamente su marginación en relación a esto), existen elementos históricos y fácticos que vienen a demostrar la progresiva influencia de esta labor en la creación normativa, y una manifestación muy peculiar de formación de jurisprudencia, sobre todo a partir de las decisiones emanadas del Tribunal Supremo Popular y su Consejo de Gobierno.

El posible reconocimiento formal de esta actividad no significaría disminuir la capacidad de nuestro ordenamiento jurídico, o la simple afirmación de sus deficiencias, sino que por el contrario sería un medio más para fortalecer su funcionamiento sistémico y perfeccionar el proceso de normatividad jurídica, elementos sumamente necesarios en el proceso de transformaciones sociales e institucionales por el que atraviesa nuestro país. 
Esta revista forma parte del acervo de la Biblioteca Jurídica Virtual del Instituto de Investigaciones Jurídicas de la UNAM

\section{CONCLUSIONES}

De los elementos expuestos en el presente artículo, deben enfatizarse algunas ideas, que planteamos a modo de conclusiones:

- De manera general, la jurisprudencia constituye una de las fuentes formales de derecho reconocidas en la doctrina jurídica, dependiendo su clasificación y reconocimiento del sistema de derecho donde se desarrolle.

- Existe una tendencia al reconocimiento de la jurisprudencia como fuente del derecho en el ordenamiento jurídico cubano, aunque esta posición no es uniforme y ha transitado por varias etapas históricas y criterios. De las posturas analizadas puede colegirse que entre las posibles manifestaciones jurisprudenciales adquieren cierto valor teórico y práctico en el contexto cubano la reiteración en los fallos de la ratio decidendi o fundamentación de la sentencia, la reiteración de las opiniones de los jueces en la solución de determinados casos (doctrina jurisprudencial) y las disposiciones del Consejo de Gobierno del Tribunal Supremo Popular (dictámenes, acuerdos e instrucciones).

- Las disposiciones del Consejo de Gobierno del Tribunal Supremo Popular son entendidas como creadoras de derecho entre operadores jurídicos y parte del sector doctrinal cubano.

- El reconocimiento de la jurisprudencia como fuente de derecho contribuiría al reforzamiento del carácter sistémico del ordenamiento jurídico; a la uniformidad de la interpretación normativa; el reconocimiento formal de la actividad creadora de derecho por parte del máximo órgano de justicia de nuestro país; a una posible definición más amplia de las fuentes del ordenamiento y su incorporación posterior a la legislación vigente (en la Constitución, preferiblemente, por su carácter ordenador) y a la configuración de un mecanismo de solución ante posibles vacíos normativos.

\section{BIBLIOGRAFÍA}

Albaladejo García, Manuel, "El cambio de jurisprudencia", Anales de la Real Academia de Jurisprudencia y Legislación (separata), núm. 28, s. p. i. 
Esta revista forma parte del acervo de la Biblioteca Jurídica Virtual del Instituto de Investigaciones Jurídicas de la UNAM

Álvarez Tabío, Fernando, El proceso contencioso administrativo, La Habana, s. e., 1954.

—

ASEFF, Lucía María, La interpretación de la ley y otros textos críticos de teoría general, Argentina, Juris, 2004.

Barreras, Antonio, "Ley Constitucional de 1934", Textos de las Constituciones de Cuba (1812- 1940), La Habana, Minerva, 1940.

BobBio, Norberto, Teoría general del derecho, Madrid, Debate, 1998.

Cañizares Abeledo, Fernando, Teoría del derecho, La Habana, Editorial Pueblo y Educación, 1979.

Carreras, Julio, Historia del Estado y el derecho en Cuba, La Habana, Editorial Pueblo y Educación, 1985.

DAVID, René y JAUfFRET-SPINOSI, Camille, Los grandes sistemas jurídicos contemporáneos, 11 a. ed., México, Universidad Nacional Autónoma de México, 2010.

Díez Picazo, Luis y Gullón, Antonio, Sistema de derecho civil, 8a. ed., Madrid, Tecnos, 1994, vol. I.

Fernández Bulté, Julio, Teoría del Estado y el derecho, La Habana, Editorial Félix Varela, 2004, t. II.

FERRARI YAUnNer, Majela, Los principios de legalidady seguridad jurídica como fundamentos del proceso de integración del derecho para colmar las lagunas de la ley en Cuba, tesis presentada en opción del grado científico de doctor en ciencias jurídicas, Facultad de Derecho Universidad de La Habana, 2010.

García Belaúnde, Domingo, El Tribunal de Garantías Constitucionales y Sociales de Cuba (1940-1952), La Habana, 1996.

García Máynez, Eduardo, Introducción al estudio del derecho, 32a. ed., México, Porrúa, 1980.

Garcini Guerra, Héctor y Reyes, Miguel, Manual de derecho administrativo. Parte general, La Habana, Universidad de la Habana, 1963, t. I.

Grillo LOngoria, Rafael, Derecho procesal civil. Teoría general del proceso civil, La Habana, Editorial Pueblo y Educación, 1993, t. I.

Guastini, Riccardo, Concepciones de las fuentes del derecho, Italia, Universidad de Génova, 1993.

HÜBNER GaLlo, Jorge Iván, "Fuentes y formas de expresión del derecho", Introducción al derecho, Santiago de Chile, Jurídica de Chile, 1976. 
Esta revista forma parte del acervo de la Biblioteca Jurídica Virtual del Instituto de Investigaciones Jurídicas de la UNAM

ITURRALDE SESMA, Victoria, Lenguaje legal y sistema jurídico. Cuestiones relativas a la aplicación de la ley, Madrid, Tecnos, 1989.

LAFUENTE BALLE, José Ma., La judicialización de la interpretación constitucional, Madrid, Colex, 2000.

Legaz Lacambra, Luis, Filosofia del derecho, Barcelona, Bosch, 1961.

MÁnov, A. et al., Teoría marxista del Estado y del derecho, La Habana, Editorial de Ciencias Sociales, 1981.

Matilla Correa, Andry et al., Temas de derecho administrativo, La Habana, Editorial Félix Varela, 2004.

Mendoza DíAz, Juan et al., Lecciones de derecho procesal civil, La Habana, Editorial Félix Varela, 2001.

Pérez Carrillo, Juan R., "Causas de indeterminación en el sistema de fuentes del derecho", Problema. Anuario de Filosofia y Teoría del Derecho, México, núm. 4, 2010.

— , "Hacia un reconocimiento jurídico-normativo de las fuentes del derecho en Cuba", Iuris Veritatis, Perú, núm. 1, 2009.

PRIETO VALDÉS, Martha, La interpretación del derecho. Criterios doctrinales y su expresión en Cuba, La Habana, s. p. i., 1999.

Recaséns Siches, Luis, Filosofia del derecho, México, Porrúa, 1959.

Rodríguez SÁnchez, Ciro Félix, "La jurisprudencia como fuente complementaria del derecho", Revista IV Conferencia Científica sobre el Derecho, Santiago de Cuba, Barquito de Papel, 1997.

VAllet De Goytisolo, Juan B., Metodología de la determinación del derecho II (parte sistemática), Madrid, Centro de Estudios Ramón Areces, Consejo General del Notariado, 1996.

, "El razonamiento judicial", Anales de la Real Academia de Jurisprudencia y Legislación, Madrid, Dykinson, núm. 39, 2009.

Villabella Armengol, Carlos Manuel, "Historiografía del poder político en Cuba: forma de gobierno en el constitucionalismo cubano", en Matilla Correa, Andry (coord.), Estudios sobre historia del derecho en Cuba, La Habana, Editorial Ciencias Sociales, 2009.

ZHIDKOv, O. et al., Fundamentos de la teoría socialista del Estado y el derecho, Moscú, Progreso, 1980. 